classification criteria, in annual follow-up (for a total of 165 patients/year) with Pulmonary Function Tests (PFTs), Health Assessment Questionnaire - Disability Index (HAQ-DI), Scleroderma Health Assessment Questionnaire (sHAQ) and Cochin Hand Function Score (CHFS). Hand disability index was assessed by $\mathrm{CHFS}$ and global disability index was assessed by HAQ and SHAQ. Patient reported arthritis activity was assessed by Visual Analogical Scale for Arthritis Activity (VAS3). Based on the median of VAS3, patients were classified in two groups and the evaluation of global and hand disability index was performed for each group. Furthermore, we assessed the correlation between the change of VAS3 and the modification of disability scores ( $\triangle \mathrm{HAQ}, \triangle \mathrm{SHAQ}, \triangle \mathrm{CHFS}$ ) over 12 months of follow-up. Following analysis of distribution, Spearman or Pearson Test were used to determine correlation coefficients, as appropriate (Prism 7).

Results: The median disease duration was 5 years (IQR 3-10). The median of VAS3 was 35 (IQR 2 - 66). In patients with VAS3 $<35$ and VAS $\geq 35$ the HAQ-DI medians were 0.625 (IQR 0.25 - 1.5) and 1.75 (IQR 1.125-2.25) respectively, $(p<0.0001)$; the sHAQ medians were 0.628 (IQR 0.255 - 1.114) and 1.701 (IQR 1.234-2.059), respectively, $(p<0.0001$ ); and the CHFS medians were 4 (IQR 0 - 19) and 28 (IQR 10 - 46) respectively, $(p<0.0001)$. A significant correlation was observed between VAS3 and HAQ $(r=0.463, p<0.0001)$, SHAQ $(r=0.651$, $p<0.0001)$, CHFS $(r=0.497, p<0.0001)$; between $\triangle$ VAS3 and $\triangle S H A Q \quad(r=0.493$, $\mathrm{p}<0.0001)$.

Conclusion: This analysis of a monocentric non-selected population supports the key role of joint involvement in determining global patient reported functional and hand disability in SSc. Severity of musculoskeletal involvement should be carefully considered when interpreting PROs in patients with SSc.

References:

[1] Sandler RD, Matucci-Cerinic M, Hughes M. Musculoskeletal hand involvement in systemic sclerosis. Seminars in Arthritis and Rheumatism (2019)

Disclosure of Interests: None declared

DOI: 10.1136/annrheumdis-2020-eular.3886

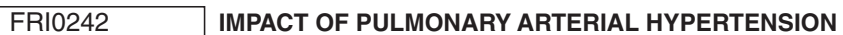 WITH OR WITHOUT INTERSTITIAL LUNG DISEASE ON SCLERODERMA: A RETROSPECTIVE COHORT STUDY FROM THE NATIONWIDE SPANISH SCLERODERMA (RESCLE) AND PULMONARY ARTERIAL HYPERTENSION (REHAP) REGISTRIES}

A. Guillén-del-Castillo ${ }^{1}$, M. López-Meseguer ${ }^{2,3}$, C. Tolosa ${ }^{4}$, A. Romás Broto ${ }^{2,3}$ D. Colunga Argüelles ${ }^{5}$, I. Blanco ${ }^{3,6}$, A. Castro ${ }^{7}$, R. López Reyes ${ }^{8}$, A. Marín Ballvé $^{9}$, I. Otero González ${ }^{10}$, V. Fonollosa-Pla ${ }^{1}$, E. Sala Llinas ${ }^{11}$, P. Escribano Subías ${ }^{12,13}$, C. P. Simeón-Aznar ${ }^{1} .{ }^{1}$ Hospital Universitario Vall d'Hebron, Unit of Autoimmune Diseases, Department of Internal Medicine, Barcelona, Spain; ${ }^{2}$ Hospital Universitario Vall d'Hebron, Department of Pneumology, Barcelona, Spain; ${ }^{3}$ Centro de Investigación Biomédica en Red de Enfermedades Respiratorias (CIBERES), Madrid, Spain; ${ }^{4}$ Hospital Universitari Parc Taulí, Department of Internal Medicine, Sabadell, Spain; ${ }^{5}$ Hospital Universitario Central de Asturias, Department of Internal Medicine, Oviedo, Spain; ${ }^{6} \mathrm{Hospital}$ Clínic, Institut d'Investigacions Biomèdiques August Pi i Sunyer (IDIBAPS), Department of Pulmonary Medicine, Barcelona, Spain; ${ }^{7}$ Hospital Universitari Sant Joan, Department of Internal Medicine, Tarragona, Spain; ${ }^{8} \mathrm{Hospital}$ Universitario y Politécnico La Fe, Department of Pneumology, Valencia, Spain; ${ }^{9}$ Hospital Clínico Universitario Lozano Blesa, IIS Aragón, Unit of Autoimmune Diseases, Department of Internal Medicine, Zaragoza, Spain; ${ }^{10} \mathrm{Hospital}$ Universitario A Coruña, Department of Pneumology, A Coruña, Spain; ${ }^{11}$ Hospital Universitario Son Espases, Department of Pneumology, Palma de Mallorca, Spain; ${ }^{12}$ Hospital Universitario 12 de Octubre, Unit of Pulmonary Hypertension, Cardiology Department, Madrid, Spain; ${ }^{13}$ Centro de Investigación Biomédica en Red de Enfermedades Cardiovasculares (CIBERCV), Instituto de Salud Carlos III, Madrid, Spain

Background: Pulmonary arterial hypertension (PAH) and interstitial lung disease (ILD) are the major life-threatening complications in systemic sclerosis (SSc). Data on the impact of PAH and/or ILD in SSc patients (pts) are limited by their low prevalence.

Objectives: To assess differences in demographic/clinical characteristics of SSc pts according to presence of PAH and how these are affected by ILD. The impact on characteristics and survival of PAH + ILD was also assessed.

Methods: We compared data on SSc pts without PAH from the Spanish registry of patients with SSc (RESCLE) (SSc pts) and SSc pts with PAH from the Spanish registry of pts with PAH (REHAP) (SSc-PAH pts). Only data common in both registries were analyzed. Sub analyses were performed according to the presence/ absence of ILD. Transplant-free survival from diagnosis of PAH was estimated using the Kaplan-Meier method.

Results: 1,579 pts with SSc (RESCLE) and 364 pts with SSc-PAH (REHAP) were analyzed. Compared to SSc pts, SSc-PAH pts had worse functional status (NYHA FC III/IV: $70.6 \%$ vs. $8.2 \%$ in SSc pts) and pulmonary function (lower mean forced vital capacity [FVC, $81.2 \pm 20.6 \%$ vs. 93.6 \pm 20 ] and diffusing capacity for carbon monoxide [DLCO, $45.3 \pm 17.7 \%$ vs. $79.0 \pm 36.6 \%]$ ). More patients had FVC/DLCO $\geq 1.4$ ( $77.8 \%$ vs. $34.8 \%)$, tricuspid regurgitation $(91.4 \%$ vs. $46.1 \%$ ) or pericardial effusion ( $30.0 \%$ vs. $5.1 \%$ ). Mean systolic pulmonary artery pressure (sPAP) was higher $(70.0 \pm 21.3$ vs. $27.5 \pm 9.1 \mathrm{mmHg}$ ) (all respectively; $\mathrm{P}<0.001$ for all). Prevalence of ILD on high-resolution computerized tomography was similar $(44.9 \%$ [ $n=92]$ vs. $41.8 \%$ [ $n=422]$ in SSc pts; $P=0.408)$. These differences were also found when splitting both cohorts according to the presence / absence of ILD. Compared to SSc-PAH pts without ILD $(n=128)$, pts with PAH + ILD $(n=92)$ had worse functional status (NYHA FC III: $69.6 \%$ vs. $55.5 \%$ in SSc-PAH pts without ILD; $P=0.036)$, lower mean FVC (70.9 \pm 21.9 vs. $86.2 \pm 18.6)$ and lowe DLCO (39.4 \pm 17.0 vs. $49.1 \pm 17.9)$ both $P<0.001$. Five-year survival rate was $35 \%$ in SSc-PAH pts with ILD vs. $45 \%$ in SSc-PAH without ILD ( $P=0.444$ [figure 1]) Conclusion: $\mathrm{PAH}$ has a profound impact on functional status, pulmonary function and right ventricle function of SSc patients, independently of presence of ILD. Despite the deleterious effect of functional status and pulmonary function, in pts with SSc and PAH, presence of concomitant ILD has no impact on 5-year survival.

Figure 1. Survival rate estimates in SSc-PAH pts with and without ILD

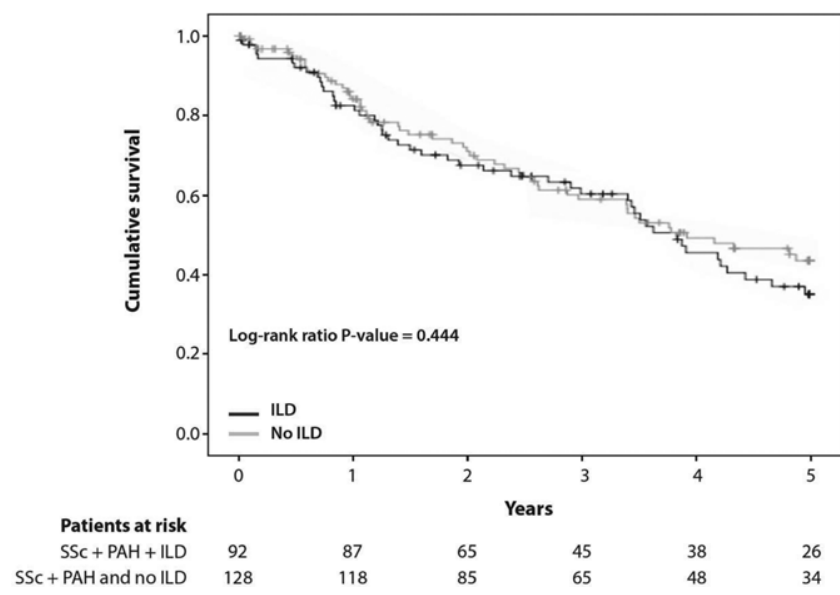

Disclosure of Interests: Alfredo Guillén-del-Castillo Consultant of: Actelion pharmaceuticals, GSK, MSD., Manuel López-Meseguer Consultant of: Actelion pharmaceuticals, GSK, MSD., Carles Tolosa Consultant of: Actelion pharmaceuticals, GSK, MSD., Antonio Romás Broto Consultant of: Actelion pharmaceuticals GSK, MSD., Dolores Colunga Argüelles Consultant of: Actelion pharmaceuticals, GSK, MSD., Isabel Blanco Consultant of: Actelion pharmaceuticals, GSK, MSD. Antoni Castro Consultant of: Actelion pharmaceuticals, GSK, MSD., Raque López Reyes Consultant of: Actelion pharmaceuticals, GSK, MSD., Adela Marín Ballvé: None declared, Isabel Otero González Consultant of: Actelion pharmaceuticals, GSK, MSD., Vicent Fonollosa-Pla Consultant of: Actelion pharmaceuticals, GSK, MSD., Ernest Sala LLinas Consultant of: Actelion pharmaceuticals, GSK, MSD., Pilar Escribano Subías Consultant of: Actelion pharmaceuticals, GSK, MSD., Carmen Pilar Simeón-Aznar Consultant of: Actelion pharmaceuticals, GSK, MSD.

DOI: 10.1136/annrheumdis-2020-eular.4302

\section{FRI0243 SARCOPENIA IS ASSOCIATED WITH MALNUTRITION IN PATIENTS WITH SYSTEMIC SCLEROSIS}

V. $\operatorname{Hax}^{1}$, R. Cavalheiro Do Espírito Santo ${ }^{1}$, E. Pena ${ }^{1}$, L. Rodrigues ${ }^{1}$, R. T. Pedo ${ }^{1}$, J. Miranda de Souza Silva ${ }^{1}$, N. Pamplona Bueno de Andrade ${ }^{1}$, A. A. Gasparin ${ }^{1}$, R. Xavier ${ }^{1}$, R. Mendonça Da Silva Chakr ${ }^{1} .{ }^{1}$ Hospital de Clínicas de Porto Alegre, Department of Rheumatology, Porto Alegre, Brazil

Background: Sarcopenia is one of the major health problems in older patients and is defined as a progressive decrease in muscle mass and function ${ }^{1}$. Sarcopenia has only rarely been studied in systemic sclerosis (SSc) and its impact in clinical characteristics of SSc is poorly investigated.

Objectives: To evaluate the associations between sarcopenia and clinical features in SSc patients.

Methods: Cross-sectional study, including 82 patients who met the ACR/EULAR 2013 classification criteria for SSc. Dual-energy X-ray absorptiometry, handgrip strength, and short physical performance battery were used to assess sarcopenia according the European Working Group on Sarcopenia in Older People's (EWG SOP) diagnostic criteria updated in $2019^{1}$. Malnutrition was evaluated according to the European Society of Clinical Nutrition and Metabolism (ESPEN) ${ }^{2}$, using the Malnutrition Universal Screening Tool (MUST) to screen risk for malnutrition. 
Results: The mean age was 60.4 years and $91.5 \%$ were women (table 1 ). Sarcopenia was identified in $15(18.3 \%)$ SSc patients. Malnutrition was diagnosed in $12(14.6 \%)$ and was more common in patients with sarcopenia $(P=0.038)$. Also, there were significant differences between patients with and without sarcopenia regarding Body Mass Index $(P=0.001)$, Fat Free Mass Index $(P<0.001)$, knee extension strength $(P=0.049)$, and Timed Up and Go test $(P=0.041)$. There were no differences regarding age, disease duration, Rodnan skin score (mRSS), FVC and DLCO.

Table 1. Clinical characteristics of SSc patients with and without sarcopenia. Data presented as number $(\%)$ of patients, except when indicated otherwise.

\begin{tabular}{|c|c|c|c|c|}
\hline Patients features & $\begin{array}{l}\text { Whole } \\
(n=82)\end{array}$ & $\begin{array}{l}\text { SSc patients with- } \\
\text { out sarcopenia } \\
\qquad(n=67)\end{array}$ & $\begin{array}{c}\text { SSc patients } \\
\text { with sarcopenia } \\
(n=15)\end{array}$ & $\begin{array}{c}P \\
\text { value }\end{array}$ \\
\hline Females & 75 (91.5) & $62(92.5)$ & $13(86.6)$ & 0.606 \\
\hline Caucasian & 68 (82.9) & $53(79.1)$ & $15(100)$ & 0.258 \\
\hline Age (years) ${ }^{b}$ & $60.4(10.6)$ & $60.2(10.3)$ & $61.5(12.3)$ & 0.678 \\
\hline Diffuse skin involvement & $16(19.5)$ & $16(23.8)$ & $0(0)$ & 0.082 \\
\hline $\begin{array}{l}\text { Disease duration } \\
\quad \text { (years) }^{\mathrm{a}}\end{array}$ & $12.8(7.5,19.2)$ & $12.7(7.1,19.2)$ & $13.4(8.9,19.8)$ & 0.324 \\
\hline Rodnan skin score ${ }^{a}$ & $4.0(2.0,10.0)$ & $5.0(2.0,10.0)$ & $2.0(2.0,10.0)$ & 0.076 \\
\hline $\begin{array}{l}\text { Interstitial lung disease } \\
\text { on HRCT }\end{array}$ & 32 (39.5) & 25 (37.3) & $7(10.4)$ & 0.737 \\
\hline FVC $(\% \text { predicted })^{b}$ & $88.4(16.6)$ & $88.4(16.9)$ & $88.3(15.3)$ & 0.991 \\
\hline DLCO $(\% \text { predicted })^{b}$ & $63.7(11.9)$ & $63.6(12.2)$ & $64.2(11.2)$ & 0.855 \\
\hline BMI $\left(\mathrm{kg} / \mathrm{m}^{2}\right)^{\mathrm{b}}$ & $25.6(4.6)$ & $26.5(4.4)$ & $21.8(4.1)$ & 0.001 \\
\hline FFMI $\left(\mathrm{kg} / \mathrm{m}^{2}\right)^{\mathrm{b}}$ & $15.6(1.7)$ & $16.1(1.6)$ & $13.8(1.2)$ & $<0.001$ \\
\hline FMI $\left(\mathrm{kg} / \mathrm{m}^{2}\right)^{\mathrm{b}}$ & $9.5(3.7)$ & $9.9(3.6)$ & $7.5(3.5)$ & 0.023 \\
\hline Malnutrition & $12(14.6)$ & $7(10.4)$ & $5(33.3)$ & 0.038 \\
\hline MUST - Low risk & $58(70.7)$ & $51(76.1)$ & $7(46.7)$ & 0.046 \\
\hline Moderate and high risk & 24 (29.3) & $16(23.9)$ & $8(53.3)$ & \\
\hline $\mathrm{HAQ}^{\mathrm{b}}$ & $0.778(0.591)$ & $0.797(0.575)$ & $0.833(0.576)$ & 0.825 \\
\hline $\begin{array}{l}\text { Timed Up and Go } \\
\text { test }(\mathrm{s})^{\mathrm{a}}\end{array}$ & $8.41(7.41,10.59)$ & $8.39(7.5,9.4)$ & $10.23(7,14)$ & 0.041 \\
\hline $\begin{array}{l}\text { Knee extension strength } \\
(\mathrm{kgf})^{\mathrm{a}}\end{array}$ & $21.40(15.65,27.52)$ & $21.70(18.05,28.35)$ & $14.82(9.5,24)$ & 0.049 \\
\hline
\end{tabular}

\section{${ }^{\text {a }}$ Median $\left(25,75^{\text {th }}\right.$ percentiles)}

${ }^{\mathrm{b}}$ Mean (standard deviation)

Abbreviations: BMI: body mass Index; DLCO: diffusion capacity of carbon monoxide; FFMI: fat free mass index; FMI: fat mass index; FVC: forced vital capacity; HAQ: Health Assessment Questionnaire; HRCT: high-resolution computed tomography; MUST: Malnutrition Universal Screening Tool; SSc: systemic sclerosis.

Conclusion: Sarcopenia is relatively common and is associated with malnutrition in patients with SSc. In our population, sarcopenia was not associated with other features related to a more severe disease. The role of sarcopenia in the prognosis of SSc needs to be better understood in longitudinal studies.

References:

[1] Cruz-Jentoft AJ, Bahat G, Bauer J, et al. Sarcopenia: Revised European consensus on definition and diagnosis. Age Ageing. 2019;48(1):16-31.

[2] Cederholm T, Bosaeus I, Barazzoni R, et al. Diagnostic criteria for malnutrition - An ESPEN Consensus Statement. Clin Nutr. 2015;34(3):335-40

Disclosure of Interests: Vanessa Hax: None declared, Rafaela Cavalheiro do Espírito Santo: None declared, Emerson Pena: None declared, Luísa Rodrigues: None declared, Renata Ternus Pedo: None declared, Jordana Miranda de Souza Silva: None declared, Nicole Pamplona Bueno de Andrade: None declared, Andrese Aline Gasparin: None declared, Ricardo Xavier Consultant of: AbbVie, Pfizer, Novartis, Janssen, Eli Lilly, Roche, Rafael Mendonça da Silva Chakr: None declared

DOI: 10.1136/annrheumdis-2020-eular.3393

\section{FRI0244 EOSINOPHILIC FASCIITIS-LIKE SECONDARY TO CHRONIC GRAFT-VERSUS-HOST DISEASE: CLINICAL DESCRIPTION OF 28 PATIENTS}

C. Hidalgo ${ }^{1}$, C. Román ${ }^{2}$, M. E. Acosta ${ }^{1}$, L. Gómez-Lechón ${ }^{1}$, M. D. Sánchez $z^{3}$, L. Pantoja ${ }^{4}$, O. Compán ${ }^{1}$, S. Pastor ${ }^{1}$, C. A. Montilla-Morales', L. López Corral' ${ }^{5}$. ${ }^{1}$ Hospital Universitario de Salamanca (Spain), Rheumatology Unit, Salamanca, Spain; ${ }^{2}$ Hospital Universitario de Salamanca, Dermatology, Salamanca, Spain; ${ }^{3}$ Hospital Clinico Universitario de Valladolid, Rheumatology, Valladolid, Spain; ${ }^{4}$ Complejo Asistencial Hospital General de Segovia, Rheumatology, Segovia, Spain; ${ }^{5}$ Hospital Universitario de Salamanca, Haematology, Salamanca, Spain

Background: Eosinophilic fasciitis (EF) is an uncommon chronic inflammatory disease characterized by myalgia, soft tissue hardening, peripheral eosinophilia and increased acute phase reactants, often triggered after strenuous physical exercise. Its appearance has been described as a rare complication after allogeneic transplantation of hematopoietic progenitors in the context of chronic graft-versus-host disease (cGVHD). Its etiopathogenesis is not well known and usually the treatment with systemic corticosteroids is effective

Objectives: Describe the clinical and transplant-related characteristics of a cohort of patients with eosinophilic fasciitis-like in the context of cGVHD

Methods: Observational, retrospective and descriptive study of the clinical characteristics of 28 patients affected by EF-like followed in a multidisciplinary consultation of cGVHD, started in March, 2014. Regular demographic variables, clinical characteristics related to the transplant and with the cGVHD, laboratory parameters, rescue therapies and their response were collected. The statistica analysis was done with Microsoft Excel 2007.

Results: Seventeen (60.7\%) patients were male and 11 (39.35\%) were women with a mean age of 48.75 years (range from 10 to 74). Acute myeloid leukemia was the most frequent cause of the transplant in 11 patients (39.3\%). Transplan related characteristics are reflected in Table 1 and the clinical manifestations, therapies received and their response in Table 2. Four (14.2\%) patients died during their follow-up, being the cause of death in 2 cases due to sepsis, and in 1 case attributable to GVHD.

Table 1. Baseline and transplant related characteristics $(\mathrm{N}=\mathbf{2 8})$

\begin{tabular}{ll}
\hline Variables & \multicolumn{1}{c}{$\mathbf{N}(\%)$} \\
\hline Donor Type (related / not related) & $13(46.4 \%) / 15(53.6 \%)$ \\
Type of conditioning (reduced intensity / myeloablative) & $18(64.25 \%) / 10(35.7 \%)$ \\
Source of cells (Peripheral blood / bone marrow) & $27(96.4 \% / 1(3.6 \%)$ \\
cGVHD type quiescent / de novo / progressive & $11(39.3 \%) / 13(46.4 \%) / 4(14.3 \%)$ \\
Other affected organs (cGVHD score) & \\
-Mouth & $6(21.4 \%)$ \\
-Eyes & $10(35.7 \%)$ \\
-Lung & $2(7.1 \%)$ \\
-Liver & $3(10.7 \%)$ \\
-Gastrointestinal tract & $0(0 \%)$ \\
-Genital & $2(7.1 \%)$ \\
-Cutaneous & $16(57.14 \%)$ \\
Global Score & $4(14.2 \%) / 14(50 \%) / 10(35.7 \%)$ \\
NIH ${ }^{1}$ (mild / moderate / severe) & \\
\hline
\end{tabular}

NIH: National Institute of Health.

Table 2. Clinical manifestations and therapies $(\mathrm{N}=28)$.

\begin{tabular}{lc}
\hline Variables & N (\%)/Median (range) \\
\hline Prodromic symptoms: yes / no & $20(71 \%) / 8(29 \%)$ \\
- Stiffness & $2(7.1 \%)$ \\
- Artromyalgia & $17(60.7 \%)$ \\
- Edema & $3(10.7 \%)$ \\
Time until first visit & $31.3 \mathrm{months}$ (range 9-73) \\
Contracture Yes / No & $18(64.3 \%) / 10(35.7 \%)$ \\
Mobility limitation (mild / moderate) & $13(46.4 \%) / 9(32.1 \%)$ \\
ECOG ${ }^{1}$ affected & $11(39.2 \%)$ \\
Eosinophilia & $17(60.7 \%)$ \\
Positive autoantibodies & $8(28.5 \%)$ \\
First line therapies (corticosteroids) & $28(100 \%)$ \\
Extracorporeal photoapheresis & $19(67.9 \%)$ \\
Therapies of 2nd line/ 3rd or more & $6(21.4 \%) / 12(42.8 \%)$ \\
Physiotherapy & $14(50 \%)$ \\
Response: complete / sequels & $10(35.7 \%) / 18(64.2 \%)$ \\
\hline
\end{tabular}

${ }^{1}$ ECOG: Eastern Cooperative Oncology Group scale to assess the quality of life

Conclusion: Nonspecific joint symptoms such as stiffness, edema or arthromyalgia in patients undergoing allogeneic transplantation of hematopoietic progenitors may be factors that predict the development of sclerotic GVHD type eosinophilic fasciitis-like and should be closely monitored in order to be able to perform early stage diagnoses of the disease. It is necessary to deepen the pathogenesis of this entity and the multidisciplinary approach to improve the prognosis of patients with GVHD

References:

[1] Inamoto Y. Arthritis Rheumatol. 2014;66(4):1044-52.

Disclosure of Interests: None declared

DOI: 10.1136/annrheumdis-2020-eular.3389

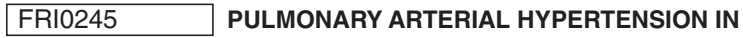 SYSTEMIC SCLEROSIS IS NEARLY ALWAYS ACCOMPANIED BY A LOW DIFFUSING CAPACITY}

A. $\mathrm{Hu}^{1}$, T. Nevskaya ${ }^{2}$, M. Baron ${ }^{2}$, J. Pope ${ }^{1}$ on behalf of Canadian Scleroderma Working Group (CSRG). ${ }^{1}$ Western University, London, Canada; ${ }^{2}$ McGill University, Montréal, Canada

Background: Scleroderma (systemic sclerosis; SSc) has high morbidity and mortality. Pulmonary hypertension $(\mathrm{PH})$ and pulmonary arterial hypertension 